\title{
BioACOUSTICAL OCEANOGRAPHY: NEW TOOLS FOR ZOOPLANKTON AND MicroneKton ReSEARCh IN tHe 1990s
}

\author{
By Charles H. Greene and Peter H. Wiebe
}

Tr OBSTACLES confronted by biological oceanographers in determining the distributional patterns of zooplankton and micronekton are formidable. Populations of these animals are patchily distributed in a three-dimensional fluid medium and continuously subjected to the physical processes of turbulent mixing and advection. Furthermore, zooplankton and micronekton are active swimmers, and thus behavior can interact with physical processes to alter their distributional patterns over a wide range of temporal and spatial scales. Overcoming such formidable obstacles is essential in pursuing one of the primary goals of biological oceanography-understanding the processes regulating the distribution of oceanic populations in time and space.

Acoustical techniques offer a number of advantages in the above pursuit; they are relatively nonintrusive, provide distributional data in near-real time. and can exhibit high spatial resolution. In addition. acoustical systems capable of producing size as well as abundance data for zooplankton and micronekton are becoming increasingly available to the oceanographic community at large. It is expected that the 1990 s will be a decade in which bioacoustical oceanography has a dramatic effect on the way zooplankton and micronekton research is conducted at sea.

\section{Development of Multiple-Frequency and}

\section{Dual-Beam Methods}

During the 1980s. methods for extracting zooplankton and micronekton size information from acoustical data have developed along two independent pathways. The first of these pathways has involved the development of multiple-frequency inversion methods to estimate acoustical size distributions from volume-backscattering data collected with several different frequencies of sound (Box 1, p. 15). Since the beginning of the decade, Holliday, Pieper. and several of their colleagues have used these inversion methods. with considerable success, to apportion estimates of zooplankton and micronekton bio-

Charles H. Greene. Ocean Resources and Ecosystems Program, Corson Hall, Comell University, Ithaca, NY 14853; Peter H. Wiebe. Biology Department. Woods Hole Oceanographic Institution. Woods Hole, MA 02543. mass concentration into different acoustical size classes (Holliday, 1980: Pieper and Holliday, 1984; Costello et al., 1989: Holliday et al., 1989). Subsequent to their efforts, first Richter (1985a,b) and then our group (Greene and Wiebe, 1988; Greene et al. $1988,1989 \mathrm{a}, \mathrm{b})$ have opted to follow a second pathway, developing an approach that involves the use of dual-beam acoustics.

Dual-beam acoustical methods were first developed in the late 1970 s for survey applications in fisheries research (see review by Ehrenberg, 1989). Subsequent refinement of these methods has made it feasible for investigators to resolve and analyze the echoes returning from individual animals as small as macrozooplankton (Box 2.p. 16). This capability, in turn. has made it possible to directly estimate the acoustical size distribution of a zooplankton and micronekton assemblage. When the results of such an analysis are combined with the results from an echo integration analysis of the corresponding volume backscattering data, estimates of numerical density and biomass concentration can be apportioned into different acoustical size classes (Greene et al. 1989a; Box 3.p. 17). To date, most field studies employing dual-beam methods have used high-frequency sound, in the range of 120 to $420 \mathrm{kHz}$, and focused their analytical efforts on micronekton and the larger size classes of zooplankton (animals exceeding approximately $4 \mathrm{~mm}$ in length). Future studies using higher frequencies of sound should allow analyses of even smaller zooplankton.

The key to using high-frequency sound in the study of zooplankton and micronekton is to deploy the acoustical transducer in a manner that gets it sufficiently close to the animals of interest. The high absorption rate of high-frequency sound by seawater sets the theoretical upper limit to the working range of all acoustical backscattering methods. In the case of a dual-beam system, the effective working range is further reduced by resolution considerations. The dual-beam method relies on the system's ability to resolve individual targets. At a given numerical density of targets, this ability diminishes as sampling volume increases. Since sampling volume increases with distance from the transducer, the system's effective range is determined in part by ambient target 


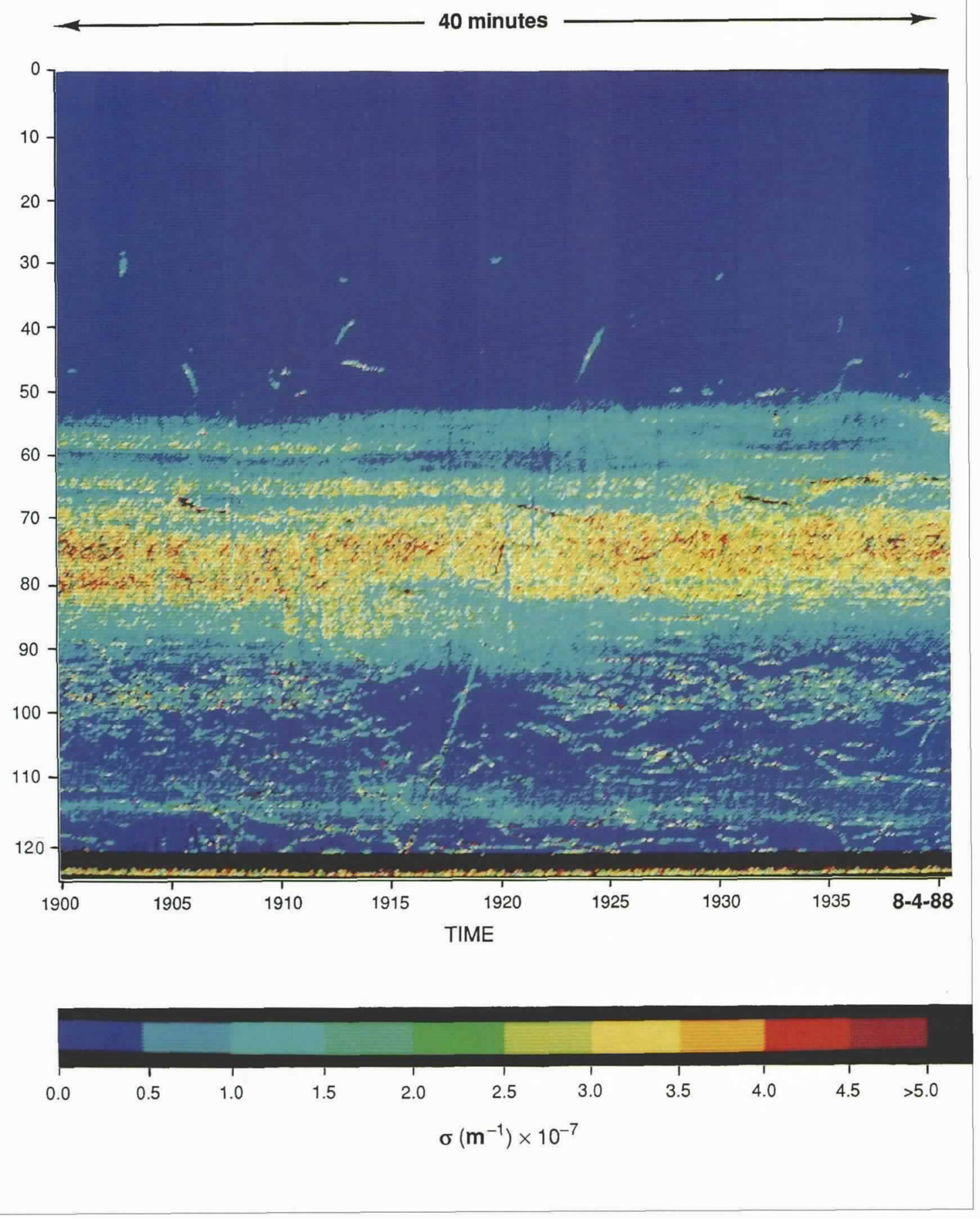

Fig. 1: (a) Color echogram of volume backscattering through time in the water column of Port Susan, Washington. The echogram, recorded from a $200 \mathrm{kHz}$ shipboard acoustical system on the evening of August 4, 1988, reveals the presence of a $45 \mathrm{~m}$ thick sound-scattering layer (SSL) between 55 and $100 \mathrm{~m}$. The fine structure of this SSL was studied with a $420 \mathrm{kHz}$ dual-beam acoustical system deployed on our remotely operated vehicle (ROV). Sound transmitted by the shipboard acoustical system was backscattered by the ROV producing a track on the echogram of the ROV's descent and ascent through the water column. 
Innovative deployment

strategies must be

devised to address

the diversity of

research problems

posed by biological

oceanographers.

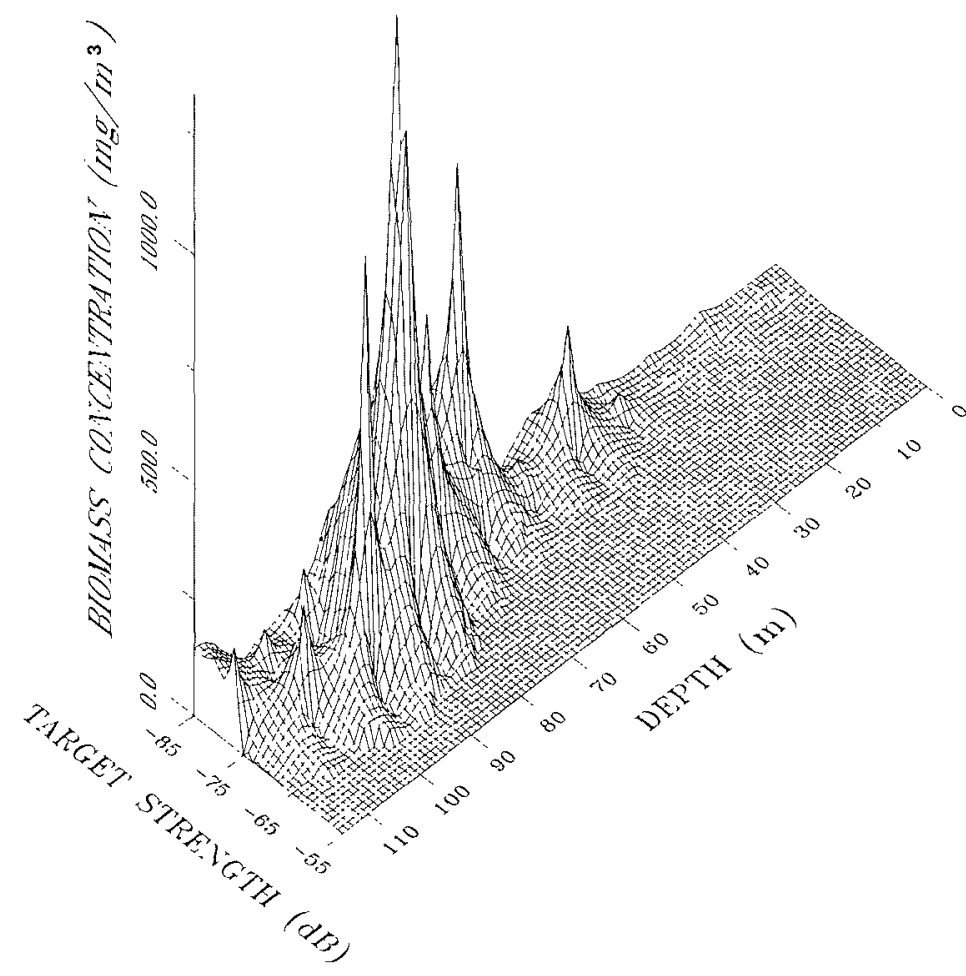

Fig. I: (b)Vertical profile of biomass concentration apportioned to different acoustical target strength classes. This profile, produced with data collected by the ROV, illustrates the importance of macrozooplankton and micronekton in the formation of SSLS.

density and in part by hardware considerations. Typical working ranges for one of our systems (frequency: $420 \mathrm{kHz}$, beamwidths: $3^{\circ}$ and $10^{\circ}$, pulse duration: $0.3 \mathrm{~ms}$ ) extend out to several meters in rich coastal environments to several tens of meters in more dilute open-ocean environments. Given these range constraints, innovative deployment strategies must be devised to address the diversity of research problems posed by biological oceanographers.

\section{Present Deployment Strategies}

To date, most of the zooplankton and micronekton field studies utilizing multiple-frequency or dualbeam acoustical methods have focused on research problems requiring information on the vertical distribution of the animal assemblage. Holliday and his colleagues have been refining a system, referred to as MAPS (Multiple-frequency Acoustical Profiling System) which can be used to profile the water column using the multiple-frequency methods they have pioneered over the last decade (Costello et al., 1989; Holliday et al., 1989). In addition to its use as a vertical profiler, MAPS has also been designed for use as a towed instrument for conducting surveys while the ship is underway. At present, MAPS represents the state of the art in multiple-frequency acoustical technology.

Dual-beam acoustical systems have been deployed in several ways for collecting data on the vertical distribution of zooplankton and micronekton. We have deployed our various dual-beam systems on manned submersibles, like Johnson Sea Link, and remotely operated vehicles (ROVs), like the Benthos Sea Rover (Greene etal., 1988; 1989a; 1989b).Vertical profiles of the type illustrated in Fig. 1 can be produced within a few hours after the completion of a submersible or ROV dive. This rapid acquisition of acoustical information can be useful in planning subsequent dive operations. One such operation, among several possibilities, involves conducting transects at predetermined depths to analyze the finescale horizontal patchiness of the animal assemblage (Fig. 2). This type of analysis is extremely difficult to accomplish by nonacoustical methods, but dualbeam systems deployed on submersibles and ROVs have proven to be well suited for such a task.

\section{Prospects for the Future}

Although the above examples demonstrate that considerable progress has been made in the last decade, it should be emphasized that the field of bioacoustical oceanography is still relatively young. Acoustical methods have the potential to resolve a number of important biological oceanographic problems, but many of the tools for doing so have not been conceived, designed, nor constructed yet.

One area deserving special attention involves the development of new instruments capable of collecting extended time series of bioacoustical data from remote locations. This type of capability has enabled 
physical and bio-optical oceanographers to make dramatic advances during the last decade (Lindstrom and Nowlin, 1989; Dicky, 1988). Recently, we have been working on an instrument development project that involves the deployment of acoustical and satellite communications systems on a spar buoy. Referred to as the BIOSPAR (Bioacoustical Sensing Platform and Relay) Project, the goal of this effort is to construct an autonomous dual-beam acoustical profiler which can measure the abundance, size structure, and vertical distribution of zooplankton and micronekton at remote oceanic locations and telemeter the data via satellite to laboratories on shore (Ehrenberg et al., 1989). Although the prototype is surface-based and downward looking, thus restricting measurements to the upper portion of the water column, BIOSPAR should provide an example of the type of free-drifting or moored instrument that can be designed and constructed by biological oceanographers to address specific problems requiring extended time series of bioacoustical data.

Another area deserving special attention involves the transfer of acoustical technology from other fields. Until this point, our discussion has emphasized multiple-frequency and dual-beam methods because these methods have provided the technological basis for most of the bioacoustical research on zooplankton and micronekton during the 1980s. New technological developments, however, in fields as disparate as physical oceanography and medical ultrasonic imaging, may prove extremely valuable to the advancement of innovative methods in bioacoustical oceanography.

Several physical and biological oceanographers have recently begun to explore the feasibility of using acoustic doppler current profilers (ADCPs) to study zooplankton and micronekton (Flagg and Smith, 1989a,b; Plueddemann and Pinkel, 1989). The most intriguing results reported to date are those of Plueddemann and Pinkel (1989) who documented the vertical distribution and migration patterns of ocean sound-scattering layers by collecting data on a custom-built ADCP and analyzing the data for temporal variations from the long-term mean in acoustical backscattering energy and vertical velocity. Although collected simultaneously, ADCP data sets of acoustical backscattering energy and vertical velocity are independent. Thus, the consistent patterns revealed by separate analyses of these two independent data sets make Plueddemann and Pinkel's interpretation especially convincing.

Although Plueddemann and Pinkel's ADCP results are the most intriguing reported to date, at least from a biological perspective, those of Flagg and Smith (1989a,b) may hold the most promise for the oceanographic community at large. Flagg and Smith have been working to "groundtruth" a productionbuilt ADCP by comparing acoustical backscattering data from the profiler with zooplankton biomass data from conventional net samples. Although their ef-
Box 1: Acoustical Size Distributions from Multiple-Frequency Volume-Backscattering Data: Inversion Methods

Acoustical size distributions can be estimated from volume backscattering data collected with several different frequencies of sound (Holliday et al., 1989). Volume backscattering is the sound energy backscattered from an insonified volume of water containing a number of acoustical targets. The intensity of volume backscattering is a function of the frequency of sound used as well as the number and scattering properties of the targets in the insonified volume. Inversion methods assume that an appropriate model can be found which relates, from each frequency used, the sound scattering of an individual target to its acoustical size class. With the volume backscattering measured at each frequency and the appropriate scattering model assumed, a series of linear equations can be solved by matrix algebra to estimate the distribution of acoustical size classes. This mathematical procedure for estimating the acoustical size distribution is referred to as solving the "inverse problem" and is the characteristic of all inversion methods.

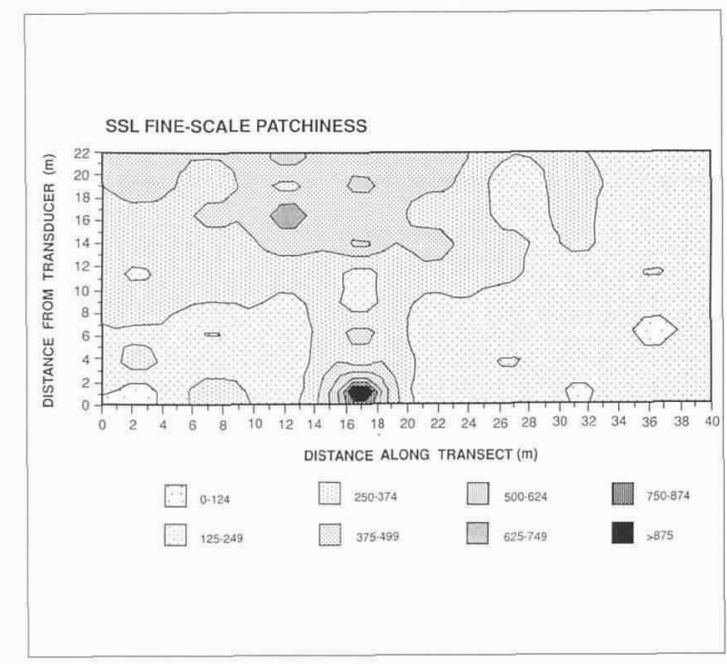

Fig. 2: Map of the fine-scale horizontal distribution of large krill (> approx. $2 \mathrm{~cm}$ ) observed during a nighttime transect through a shallow sound-scattering layer in the Gulf of Maine. (Units in krill/1000 ${ }^{3}$.) 


\section{Box 2: Acoustical Size Distributions from Target Echo Data: Dual- and Split-Beam Methods}

Acoustical size distributions can be estimated from target echo data collected with dual- or split-beam acoustical systems (Ehrenberg, 1989a). Although the signal acquisition and processing procedures of the dual- and split-beam methods are different, the data outputs are similar.

In both methods, the acoustical sizes and ranges from the transducer of individual animals are estimated from their echo returns. Acoustical sizes are typically reported as target strengths, which are calculated as follows:

$$
\mathrm{TS}=10 \log \sigma_{\mathrm{bs}}=10 \log \left(\mathrm{I}_{\mathrm{r}} \mathrm{I}_{\mathrm{i}}\right)
$$

where TS is the target strength, $\sigma_{b s}$ is the backscattering cross section, $\mathrm{I}_{\mathrm{r}}$ is the intensity of the echo return, and $\mathrm{I}_{\mathrm{i}}$ is the incident intensity. Target strength estimates require information on the intensities of echo returns and the positions of targets in the beam (Fig. 2.1). This latter piece of information is acquired in the dual-beam method by comparing the echo intensities from a single target detected at two separate receiving elements of a dual-beam transducer. In contrast, the split-beam method acquires the same information by determining the relative phase shift in a given target's echo return at different quadrants of a split-beam transducer.

Irrespective of which of the above methods is used, the target strength estimates from animals are combined to estimate an acoustical size distribution for the animal assemblage. With appropriate calibration experiments, this acoustical size distribution can be used to estimate the actual size distribution of the animal assemblage.

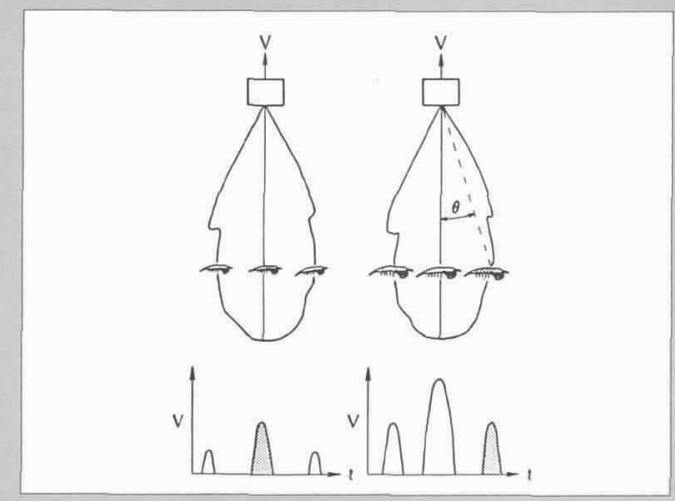

Fig. 2.1: Output voltages from an echo sounder due to small and large targets moving through the acoustical beam. Voltages are maximal when targets are on the main axis and taper off as targets approach the edges of the beam. For a typical single-beam acoustical system, the target's position in the beam is unknown; therefore, the system cannot distinguish between a small target on axis (shaded on left) and a large target at the beam's edge (shaded on right). A dual-or splitbeam system can make this distinction by determining the target's position in the beam. (Figure reproduced from Greene et al., 1989a). forts have revealed several unforeseen hardware problems, Flagg and Smith have clearly demonstrated the ADCP's potential for collecting useful, quantitative data on zooplankton and micronekton abundance. Once the hardware problems are worked out, the payoffs will be large since production-built ADCPs have rapidly infiltrated the research programs of many physical oceanographers as well as the UNOLS fleet. The capability to collect biological and physical data sets simultaneously from the same instrument will create many opportunities for collaborative research in the future.

In addition to technology transfer associated with instrument development, bioacoustical oceanography has and will continue to benefit from the transfer of signal processing techniques from other fields. For example, signal processing techniques which use the phase as well as the amplitude spectrum of the acoustical backscattering energy have been developed by physical oceanographers to study ocean microstructure (Farmer and Huston, 1988). Measurements of the phase spectrum, especially at several frequencies, may provide valuable information on target indentity beyond the simple acoustical size measurements currently being made. Likewise, methods in materials science and ultrasonic imaging, transferred from the fields of engineering and medicine, respectively, may prove invaluable in developing new techniques for target recognition. Prospects for the future in this area are especially bright.

In conclusion, recent and ongoing developments in bioacoustical oceanography hold much promise for the future. Much as Hensen's (1887) development of quantitative net sampling methods in the 1880 s and 1890 s revolutionized zooplankton and micronekton research in the twentieth century, so too might the development of acoustical methods in the 1980s and 1990s revolutionize such research in the twenty-first century.

\section{Acknowledgements}

First, we thank the Oceanic Biology Program of the Office of Naval Research and the Oceanographic Technology Program of the National Science Foundation for supporting our research efforts in the field of bioacoustical oceanography. Second, we thank our engineering colleagues at BioSonics, the Woods Hole Oceanographic Institution, and the University of Washington's Applied Physics Laboratory (APL) for the long hours and difficulties they have endured in getting many of the instruments described in this 
paper operational. Finally, we thank Robert Miyamoto, APL, and Letitia Stone, BioSonics, Inc., for preparing most of the paper's illustrations.

\section{References}

Costello, J.H., R.E. Pieper, and D.V. Holliday, 1989: Comparison of acoustic and pump sampling techniques for the analysis of zooplankton distributions. J. Plankton Res., 11, 703709.

Dickey, T.D., 1988: Recent advances and future directions in multi-disciplinary in situ oceanographic measurement systems. In: Toward a Theory on Biological-Physical Interactions in the World Ocean. B.J. Rothschild, ed., Kluwer Acad. Publ., Dordrecht, 555-598.

Ehrenberg, J.E., 1989: A review of target strength estimation techniques. In: Underwater Acoustical Data Processing. Y.T. Chan, ed., Kluwer Acad. Publ., Dordrecht, 161-176.

Ehrenberg, J.E., P.H. Wiebe, W.H. Hanot, H.G. McMichael, and R.T. Miyamoto, 1989: BIOSPAR, a buoy system for acoustic monitoring of biological populations. Oceans '89, 4, Mar. Tech. Soc. and IEEE, Seattle, WA, 10321035 .

Farmer, D.M., and R.D. Huston, 1988: Novel applications of acoustic backscatter to biological measurements. In: Toward a Theory on Biological-Physical Interactions in the World Ocean. B.J. Rothschild, ed., Kluwer Acad. Publ., Dordrecht, 599-614.

Flagg, C.N., and S.L. Smith, 1989a: On the use of the acoustical Doppler current profiler to measure zooplankton abundance. Deep-Sea Res., 36, 455-474.

Flagg, C.N., and S.L. Smith, 1989b: Zooplankton abundance measurements from acoustic doppler current profilers. Oceans '89, 5, Mar. Tech. Soc. and IEEE, Seattle, WA, 1318-1323.

Greene, C.H., and P.H. Wiebe, 1988: New developments in bioacoustical oceanography. Sea Technol., 29, 27-29.

Greene, C.H., P.H. Wiebe, and J. Burczynski, 1989a: Analyzing zooplankton size distributions using high-frequency sound. Limnol. Oceanogr., 34, 129-139.

Greene, C.H., P.H. Wiebe, and J. Burczynski, 1989b: Analyzing distributions of zooplankton and micronekton using highfrequency, dual-beam acoustics. Progr. Fish. Acoust., II, 45-54.

Greene, C.H., P.H. Wiebe, J. Burczynski, and M.J. Youngbluth, 1988: Acoustical detection of high-density demersal krill layers in the submarine canyons off Georges Bank. Science, 241, 359-361.

Hensen, V., 1887: Ueber die Bestimmung des Planktons oder des im meere treibenden Materials in Pflanzen und Thieren. Wiss. Meeresunters. Berlin, 5, 1-108.

Holliday, D.V., 1980: Use of frequency diversity for marine biological measurements. In: Advanced Concepts in Ocean Measurements for Marine Biology. F.P. Diemer et al., eds., Univ. South Carolina Press, Columbia, 423-460.

Holliday, D.V., R.E. Pieper, and G.S. Kleppel, 1989: Determination of zooplankton size and distribution with multi-frequency acoustic technology. J. Cons. Int. Explor. Mer., 46(1), $52-$ 61.

Lindstrom, E.J., and W.D. Nowlin, Jr., 1989: WOCE: Impetus for new instrument development. Sea Technol., 30, 31-37.

Pieper, R.E., and D.V. Holliday, 1984: Acoustical measurements of zooplankton distributions in the sea. J. Cons. Int. Explor. Mer., 41, 226-238.

Plueddemann, A.J., and R. Pinkel, 1989: Characterization of the patterns of diel migration using Doppler sonar. Deep-Sea Res., 36, 509-530.

Richter, K.E., 1985a: Acoustical scattering at $1.2 \mathrm{MHz}$ from individual zooplankters and copepod populations. DeepSea Res., 32, 149-161.

Richter, K.E., 1985b: Acoustic determination of small-scale distributions of individual zooplankters and zooplankton aggregations. Deep-Sea Res., 32, 163-182. $\square$
Box 3: Size-Based Abundance Estimates from Dual-Beam and Echo Integration Analyses

The dual-beam method is used to estimate the acoustical size distribution of an animal assemblage. Echo integration is used to estimate the relative abundance of animals in the assemblage. In combination, the two procedures can be used to estimate the absolute abundance of animals in the assemblage and apportion that abundance among the various acoustical size classes. A description of how these procedures are combined is provided below.

Echo integration yields a quantity referred to as the volume backscattering coefficient, sv, which is the sum of the backscattering from all targets within the insonified volume. The volume backscattering coefficient is related to the numerical density in acoustical size class $\mathrm{i}, \mathrm{N}_{\mathrm{i}}$, by the following equation:

$$
\mathrm{sv}=\Sigma \mathrm{N}_{\mathrm{i}} \times \sigma_{\mathrm{bsi}}
$$

where $\sigma_{b s i}$ is the backscattering cross section of targets in acoustical size class i. The volume backscattering coefficient is also related to the total numerical density of targets, $N_{1}$, by the following equation:

$$
\mathrm{sv}=\mathrm{N}_{\mathrm{t}} \times \bar{\sigma}_{\mathrm{bs}}
$$

where $\bar{\sigma}_{b s}$ is the mean backscattering cross section of all targets in the insonified volume. This last equation can be expanded further as follows:

$$
\mathrm{Sv}=\mathrm{N}_{\mathrm{t}} \times \bar{\sigma}_{\mathrm{bs}}=\mathrm{N}_{\mathrm{t}} \Sigma \mathrm{p}_{\mathrm{i}} \times \sigma_{\mathrm{bsi}}
$$

where $p_{i}$ is the proportion of targets in acoustical size class $i$. None of the variables on the right side of the above equations can be solved for by echo integration alone.

The dual-beam method provides the acoustical size distribution information necessary to solve for the unknowns in the above equations. Specifically, $\bar{\sigma}_{b s}$ and the distribution of $p_{i}$ 's are estimated by this procedure. Thus, equation 3.2 can be rearranged and solved for the total numerical density of targets, $\mathrm{N}_{\mathrm{t}}$, in the insonified volume. Once $\mathrm{N}_{\mathrm{t}}$ is known, it can be apportioned among the various acoustical size classes with the following equation derived from the relationship specified in equations 3.1 and 3.3:

$$
\mathrm{N}_{\mathrm{i}}=\mathrm{N}_{\mathrm{t}} \times \mathrm{p}_{\mathrm{i}}
$$

In addition to numerical density, biomass concentration can be apportioned among the various acoustical size classes if an estimate of the mean biomass for individuals in each acoustical size class is available from calibration experiments. 